\title{
Scaffold-free and label-free biofabrication technology using levitational assembly in a high magnetic field
}

Citation for published version (APA):

Parfenov, V. A., Mironov, V. A., van Kampen, K. A., Karalkin, P. A., Koudan, E. V., Pereira, F. DAS., Petrov, S. V., Nezhurina, E. K., Petrov, O. F., Myasnikov, M., Walboomers, F. X., Engelkamp, H., Christianen, P., Khesuani, Y. D., Moroni, L., \& Mota, C. (2020). Scaffold-free and label-free biofabrication technology using levitational assembly in a high magnetic field. Biofabrication, 12(4), [045022]. https://doi.org/10.1088/1758-5090/ab7554

Document status and date:

Published: 01/10/2020

DOI:

10.1088/1758-5090/ab7554

Document Version:

Publisher's PDF, also known as Version of record

Document license:

Taverne

Please check the document version of this publication:

- A submitted manuscript is the version of the article upon submission and before peer-review. There can be important differences between the submitted version and the official published version of record.

People interested in the research are advised to contact the author for the final version of the publication, or visit the DOI to the publisher's website.

- The final author version and the galley proof are versions of the publication after peer review.

- The final published version features the final layout of the paper including the volume, issue and page numbers.

Link to publication

\footnotetext{
General rights rights.

- You may freely distribute the URL identifying the publication in the public portal. please follow below link for the End User Agreement:

www.umlib.nl/taverne-license

Take down policy

If you believe that this document breaches copyright please contact us at:

repository@maastrichtuniversity.nl

providing details and we will investigate your claim.
}

Copyright and moral rights for the publications made accessible in the public portal are retained by the authors and/or other copyright owners and it is a condition of accessing publications that users recognise and abide by the legal requirements associated with these

- Users may download and print one copy of any publication from the public portal for the purpose of private study or research.

- You may not further distribute the material or use it for any profit-making activity or commercial gain

If the publication is distributed under the terms of Article $25 \mathrm{fa}$ of the Dutch Copyright Act, indicated by the "Taverne" license above, 


\section{PAPER}

Scaffold-free and label-free biofabrication technology using levitational assembly in a high magnetic field

To cite this article: Vladislav A Parfenov et al 2020 Biofabrication 12045022

View the article online for updates and enhancements.

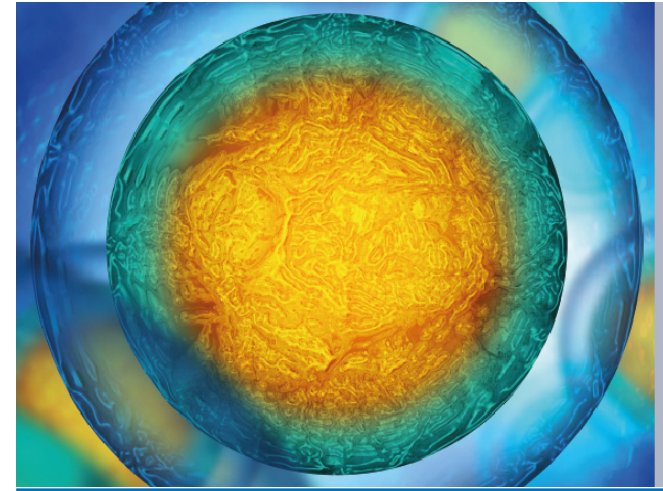

Biophysical Society $\quad$ IOP | ebookS

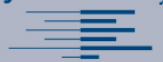

Your publishing choice in all areas of biophysics research.

Start exploring the collection-download the first chapter of every title for free. 


\title{
Biofabrication
}

\section{PAPER}

CrossMark

\section{Scaffold-free and label-free biofabrication technology using \\ levitational assembly in a high magnetic field}

RECEIVED
17 September 2019

(1)

24 January 2020

ACCEPTED FOR PUBLICATION

12 February 2020

PUBLISHED

4 August 2020

\author{
Vladislav A Parfenov ${ }^{1,7,8} \oplus$, Vladimir A Mironov ${ }^{1,7,8}$, Kenny A van Kampen $^{2}$, Pavel A Karalkin ${ }^{1,3}$, \\ Elizaveta V Koudan ${ }^{1}$, Frederico DAS Pereira ${ }^{1}$, Stanislav V Petrov ${ }^{1}$, Elizaveta K Nezhurina ${ }^{3}$, Oleg F Petrov ${ }^{4}$, \\ Maxim I Myasnikov ${ }^{4}$, Frank X Walboomers ${ }^{5}$, Hans Engelkamp ${ }^{6} \oplus$, Peter Christianen ${ }^{6}$, Yusef D Khesuani ${ }^{1}$, \\ Lorenzo Moroni ${ }^{2}$ (1) and Carlos Mota ${ }^{2,8}$ \\ 1 Laboratory for Biotechnological Research '3D Bioprinting Solutions', Moscow, Russia \\ 2 Department of Complex Tissue Regeneration, MERLN Institute for Technology-Inspired Regenerative Medicine, Maastricht University, \\ The Netherlands \\ 3 National Medical Research Radiological Center, Moscow, Russia \\ 4 Joint Institute for High Temperatures, Russian Academy of Sciences, Moscow, Russia \\ Department of Biomaterials, Radboud University Medical Center, PO Box 9101, 6500 HB, Nijmegen (309), The Netherlands \\ 6 High Field Magnet Laboratory (HFML_EMFL), Radboud University, Toernooiveld 7, 6525 ED Nijmegen, The Netherlands \\ Both authors contributed equally to this paper. \\ 8 Authors to whom any correspondence should be addressed. \\ E-mail: vapar@mail.ru,vladimir.mironov54@gmail.com and c.mota@maastrichtuniversity.nl
}

Keywords: tissue spheroids, magnetic levitation, biofabrication, high magnetic field, gadolinium salt

Supplementary material for this article is available online

\begin{abstract}
The feasibility of magnetic levitational bioassembly of tissue-engineered constructs from living tissue spheroids in the presence of paramagnetic ions (i.e. $\mathrm{Gd}^{3+}$ ) was recently demonstrated. However, $\mathrm{Gd}^{3+}$ is relatively toxic at concentrations above $50 \mathrm{mM}$ normally used to enable magnetic levitation with $\mathrm{NdFeB}$-permanent magnets. Using a high magnetic field (a $50 \mathrm{~mm}$-bore, $31 \mathrm{~T}$ Bitter magnet) at the High Field Magnet Laboratory at Radboud University in Nijmegen, The Netherlands, we performed magnetic levitational assembly of tissue constructs from living spheroids prepared from the SW1353 chondrosarcoma cell line at $0.8 \mathrm{mM} \mathrm{Gd}^{3+}$ containing salt gadobutrol at $19 \mathrm{~T}$ magnetic field. The parameters of the levitation process were determined on the basis of polystyrene beads with a $170 \mu \mathrm{m}$ diameter. To predict the theoretical possibility of assembly, a zone of stable levitation in the horizontal and vertical areas of cross sections was previously calculated. The construct from tissue spheroids partially fused after $3 \mathrm{~h}$ in levitation. The analysis of viability after prolonged exposure $(1 \mathrm{~h})$ to strong magnetic fields (up to $30 \mathrm{~T}$ ) showed the absence of significant cytotoxicity or morphology changes in the tissue spheroids. A high magnetic field works as a temporal and removal support or so-called 'scaffield'. Thus, formative biofabrication of tissue-engineered constructs from tissue spheroids in the high magnetic field is a promising research direction
\end{abstract}

\section{Introduction}

Since the early 1990s, several authors have demonstrated the potential of levitation in air of water and other diamagnetic substances [1, 2]. Ikezoe et al have succeeded in levitating, in the atmosphere, a paramagnetic water ball containing $\mathrm{CuSO}_{4}$ (they have named this phenomena 'magneto-Archimedes levitation'); although before this it was claimed that it should be impossible to levitate paramagnetic substances [2]. Since then, principles of magnetic levitation are being used successfully and broadly in different areas of technology and industries [3]. In 1997, Geim performed the diamagnetic levitation of a living organism (frog) in the air at the High Field Magnet Laboratory at Radboud University in Nijmegen, The Netherlands, which was a breakthrough in the area of magnetic levitation [4]. In cell biology, as cells or tissue spheroids (cell aggregates) are considered to be diamagnetic, it has been proposed that their levitation could be achieved by using a paramagnetic medium. The most commonly used paramagnetic agents are 
gadolinium (III) chelates. This approach implies the creation of a 3D magnetic trap for diamagnetic objects in an aqueous solution of paramagnetic ions. Winkleman et al demonstrated trapping of polystyrene spheres and of various types of living cells: the mouse fibroblast cell line NIH-3T3, yeast (Saccharomyces cerevisiae), and algae (Chlamydomonas reinhardtii) using permanent magnets in the $40 \mathrm{mM}$ paramagnetic gadolinium salt solution [5]. After studies of Whitesides's group [6] and a series of publications from Demirci's group (both from Harvard University) [7-10] several research teams around the world also demonstrated that a magnetic levitational bioassembly using a paramagnetic medium is technologically feasible [11, 12]. It is worth mentioning that this approach avoids the use of 'labels' of any type, namely magnetic nanoparticles which are cytotoxic and are proved to accumulate in human organisms after implantation of tissue-engineered constructs containing nanoparticles [13-15].

Gadolinium(III) chelates are broadly used as contrast agents which are approved by the FDA for application in clinical imaging, such as MRI [16]. For our experiments we selected an FDA-approved $\mathrm{Gd}^{3+}$-agent with known lowest possible toxicitygadobutrol (trade name 'Gadovist'). However, the high concentrations of $\mathrm{Gd}^{3+}$ can be potentially toxic for cells and tissue spheroids, and a certain risk exists for osmotic pressure imbalance due to excessive use of ions in a paramagnetic medium. This undesirable toxicity of gadolinium represents the main challenge in further development of this direction. We are facing an obvious dilemma- a high concentration of gadolinium enables magnetic levitation but is relatively toxic, whereas a low non-toxic concentration of gadolinium does not allow magnetic levitation with permanent magnets. In such a situation, some researchers used a low concentration of gadolinium to show absence of toxicity, and then a higher concentration of gadolinium to enable magnetic levitation [17]. There are three potential strategies to resolve this dilemma: (i) develop a non-toxic gadolinium salt; (ii) perform magnetic levitation at a low concentration of gadolinium under conditions of microgravity in Space; and (iii) perform levitation at a low concentration of gadolinium using a high magnetic field. There is no doubt that the already ongoing systematic exploration of all these three alternative strategies will eventually advance the emerging and promising fields of magnetic levitational bioassembly and biofabrication. At least, theoretically, it is possible to develop gadolinium salts with low toxicity using chelation. Magnetic levitational bioassembly experiments under microgravity conditions have already been successfully performed on the Russian segments of The International Space Station in December 2018, and the results will soon be analyzed and published. Thus, the first two strategies are already under consideration. Now, we have also focused on the realization of the third strategy-a magnetic levitational bioassembly of tissue constructs in a high magnetic field.

Here, we report a first time successful magnetic levitation bioassembly of 3D tissue constructs from tissue spheroids fabricated from the SW1353 chondrosarcoma cell line at 100 times lower, non-toxic concentration of a paramagnetic medium (aqueous gadolinium salt solution) in a high magnetic field. We show the absence of any toxic effects of either the high magnetic field or the low concentration of gadolinium on the viability of the cells and tissue constructs. Our data demonstrate that magnetic levitational bioassembly at a non-toxic concentration of gadolinium is technologically feasible. Moreover, our experimental results confirmed the validity of proposals to use a magnetic levitational bioassembly in a high magnetic field as a cost-effective alternative to microgravity research at The International Space Station [18-20]. We are convinced that the described methodological approach can be further used for systematic studies of the biological effects of microgravity on living objects at high magnetic fields on Earth.

\section{Materials and methods}

\subsection{Cell culture}

The human chondrosarcoma cell line SW1353 was purchased from the American Type Culture Collection (ATCC) (Cat. \# HTB-94) and cultured in DMEM/F12 medium with $10 \%$ fetal bovine serum (FBS) in humidified atmosphere $5 \% \mathrm{CO}_{2}$ at $37^{\circ} \mathrm{C}$. Cells were routinely split at $85 \%-95 \%$ confluence using mild enzymatic dissociation with a $0.25 \%$ trypsin/0.53 mM EDTA solution (all reagents from Gibco, USA).

\subsection{Fabrication of tissue spheroids}

Tissue spheroids were prepared using 81-well MicroTissues 3D Petri dish micromolds (Sigma-Aldrich, USA) according to the manufacturer's protocol. Briefly, $190 \mu \mathrm{l}$ of SW1353 cell suspension with concentration $3.4 \times 10^{6}$ cells per $\mathrm{ml}$ was placed into each agarose mold, incubated for $1 \mathrm{~h}$ and then covered with complete growth media. The resultant tissue spheroids consisted of $8 \times 10^{3}$ cells.

\subsection{Assessment of tissue spheroid viability}

The viability of tissue spheroids in the presence of paramagnetic gadobutrol ('Gadovist', Bayer Pharma AG, Germany) was assessed using the CellTiter-Glo 3D kit (Promega, USA). Thus, four-day-old spheroids were placed in $0,0.8,50$ and $100 \mathrm{mM}$ gadobutrol for $24 \mathrm{~h}$. The reagent was added for $30 \mathrm{~min}$, and then luminescence was recorded using a VICTOR X3 multilabel plate reader (Perkin Elmer, USA). The influence of a magnetic field with $19 \mathrm{~T}$ intensity in the presence of an effective gadobutrol concentration $(0.8$ $\mathrm{mM}$ ) on cell viability was analyzed using the Live/ 
Dead Cell Double Staining Kit (Sigma-Aldrich, USA). After the exposure in an experimental setup, the spheroids were incubated with calcein AM and propidium iodide at $37^{\circ} \mathrm{C}$ for $1 \mathrm{~h}$. After washing with PBS, the spheroids were imaged by fluorescent microscopy (Nikon Eclipse Ti-E, Japan).

\subsection{Spheroid fusion assay}

A spheroid fusion assay was performed using ultralow-adhesive spheroid microplates (Corning, USA) (Corning, cat.\# 4520). Pairs of tissue spheroids were placed in contact in the presence of $0,0.8$ and $100 \mathrm{mM}$ gadobutrol concentrations and incubated for five days. Bright-field images of spheroid doublets were obtained at the time points $0,1,2,3,4,6,8,12$ and 24 h. Contact intersphere angles were measured using Image J 1.48v software (NIH, Bethesda, MD, USA) and plotted as a function of time using GraphPad Prism software (GraphPad Software, Inc., La Jolla, CA).

\subsection{Histology and electron microscopy}

Samples were fixed in PBS-buffered $4 \%$ paraformaldehyde solution, then put in melted $2 \%$ agarose gel and finally embedded in paraffin (Merck, Germany). After dewaxing, serial sections with a thickness of $4 \mu \mathrm{m}$ were cut and routinely stained with hematoxylin-eosin (Sigma-Aldrich, Germany). For transmission electron microscopy (TEM) examination samples were fixed with $2.5 \%$ glutaraldehyde in $0.1 \mathrm{M}$ cacodylate buffer, and post-fixed with $1 \%$ osmium tetroxide in the buffer containing $1.5 \%$ potassium ferricyanide. Then, the samples were dehydrated in ethanol, and embedded in the Epon resin. Ultrathin sections were obtained using a Leica Ultracut UCT ultramicrotome and mounting on Formvar-coated copper grids. The sections were stained with $2 \%$ uranyl acetate in water and lead citrate. The sections were observed in a Tecnai T12 electron microscope equipped with an Eagle $4 \mathrm{k} \times 4 \mathrm{k}$ CCD camera (Thermo Fisher Scientific, The Netherlands).

\subsection{Magnetic experimental setup}

To create a magnetic field, a $50 \mathrm{~mm}$-bore, 31 Tesla Bitter magnet was used (figures 1(a), (b)). To ensure the temperature regime of $37^{\circ} \mathrm{C}$, a water thermostat was connected to the working area of the magnet. To place the cuvette with the material inside the magnet, a custom-designed holder was used (figure 1(c)), which fixed the cuvette at a certain height and used a mirrors and lenses system to allow the observation of the levitation and assembly process. LEDs were fixed to the holder to illuminate the working area. A glass flask with a plastic screw cap was used as a cuvette and filled with culture medium containing polystyrene beads or tissue spheroids with different concentrations of the gadobutrol. A camera was used for registration of the assembly process.

\subsection{Molecular dynamics simulation of the polystyrene beads and tissue spheroids in the magnetic field of the Bitter magnet}

The molecular dynamics (MD) modeling was carried out as described previously [11, 21-23]. We assumed that all particles in MD calculations were spherical, with the same size and mass $m_{p}$. For modeling dynamics of the diamagnetic polystyrene particles in the magnetic field of the Bitter electromagnet, we have numerically solved the system of the Newton equations for all the particles $(1<k<N)$ :

$m_{p} \frac{d^{2} \mathbf{r}_{k}}{d t^{2}}=\sum_{l} F\left(\left|\mathbf{r}_{k l}\right|\right) \frac{\mathbf{r}_{k l}}{\left|\mathbf{r}_{k l}\right|}+\mathbf{F}_{k B}+\mathbf{f}_{k}+\mathbf{f}_{g}+\mathbf{f}_{b}$

where $N$ is the number of particles for which the simulation was performed, $k$ is the particle serial number in the ensemble, $l$ is the serial numbers of surrounding particles and $\mathrm{r} k, \mathrm{r} l$ is the position of the center of a particle $k$ and $l$, respectively, $\mathbf{r}_{k l}=\mathbf{r}_{k}-\mathbf{r}_{l}$. The first term in the right-hand part of equation (1) is the Lennard-Jones interaction with other particles, the second term is the interaction with the magnetic field of the trap $\left|\mathbf{F}_{k B}\right|=\left(\chi_{p}-\chi_{s}\right) B \nabla B$ (figure 1) and $\chi_{p}, \chi_{s}-$ is the magnetic susceptibility of the particle and solution, respectively. The third term is the force of viscous friction against the continuum liquid which is determined by the Stokes formula $\mathbf{f}_{k}=-3 \pi d \eta \mathbf{u}_{k}, \eta$ is the viscosity of the gadobutrol suspension, $d$ is the particle diameter and $\mathbf{u}_{k}=d \mathbf{r}_{k} / d t$ is the particle velocity relative to the stationary liquid, the fourth and the fifth terms are a force of gravity $\mathbf{f}_{g}$ and buoyancy force $\mathbf{f}_{b}$ acting on the particle. Numerical simulation was performed for the number of particles $N=400$.

The simulation was performed for polystyrene beads and tissue spheroids with densities $\rho=1.0405$ $\mathrm{g} \mathrm{cm}^{-3}$ and $\rho=1.05 \mathrm{~g} \mathrm{~cm}^{-3}$, respectively. At the first step, particles were distributed randomly within the computational domain with initial zero velocity. The computational domain corresponds to the internal volume of the experimental cylindrical cell$\mathrm{R} 7 \times 25 \mathrm{~mm}$

\section{Results}

3.1. Modelling of the magnetic field and assembly of a construct in the magnetic field

To simulate a levitation assembly, we modelled the magnetic field generated by a Bitter magnet (figure 1(a)). The optimal position along the vertical axis of the Bitter magnet was calculated from the measured vertical field profile, following the methodology described by Berry and Geim [4]. The stable zone was determined to be $88 \pm 6 \mathrm{~mm}$ above the field center (figure 2).

For modeling of the assembly process, we carried out MD simulation for the polystyrene beads. MD simulation showed that the polystyrene beads start to cluster after $4 \mathrm{~min}$, achieving a stable assembled 


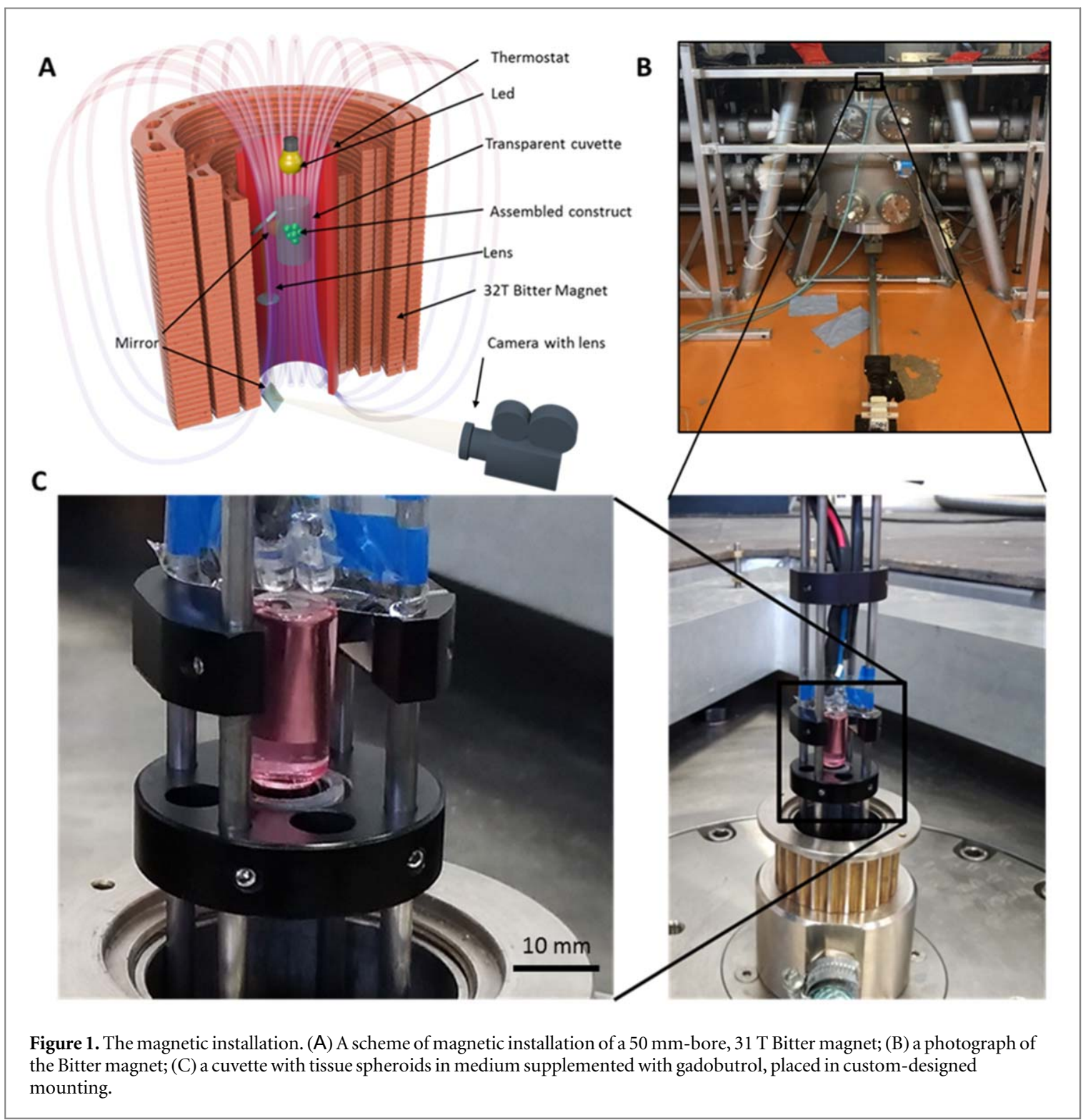

construct in $10 \mathrm{~min}$ (figures 3(a), (d)). The experimental and simulated shapes of the assembled constructs have a good similarity in the final ellipsoid volume (figures 3(b), (c)). The small difference between experimental and simulated kinetics can be attributed to the initial parameters of the modelling. In simulation, the initial speed of the particles was equal to 0 , and the particles were equally distributed throughout. In the experiment, firstly, the particles lay at the bottom of the cuvette; secondly, it took $5 \mathrm{~min}$ to get the desired magnetic field intensity. Because of this we moved the cuvette up and down to stir up the particles. As a result, the particles peaked up the initial speed in the different directions, which contributed to the difference between the simulation and experimental results.

\subsection{Assembly of constructs (aggregates) from} polystyrene beads in the high magnetic field

The polystyrene beads were used as physical analogs of living tissue spheroids with similar sizes and shapes.
The levitation assembly of the polystyrene bead construct occurred at a magnetic field intensity of $22 \mathrm{~T}$ in the presence of $0.5 \mathrm{mM}$ gadobutrol. The assembly occurred in $10 \mathrm{~min}$ (figure 5(a)). The results of the magnetic levitation assembly of the construct from polystyrene beads confirmed developed predictive mathematical models.

\subsection{Viability of tissue spheroids}

In this study we selected the human chondrosarcoma cell line SW1353 as a reliable well-characterized human cell source for fabrication of tissue spheroids [24-26]. The employed fabrication method enabled the formation of tissue spheroids with regular sizes and shapes, which is essential for the standardization of magnetic levitation assembly experiments, as well as for the estimation of the possible toxicity of a high magnetic field and paramagnetic medium (figure 4(a)). The spheroid fusion assay showed that at a low concentration of gadolinium salt $(0.8 \mathrm{mM}$ gadobutrol) tissue spheroids can fuse, which 


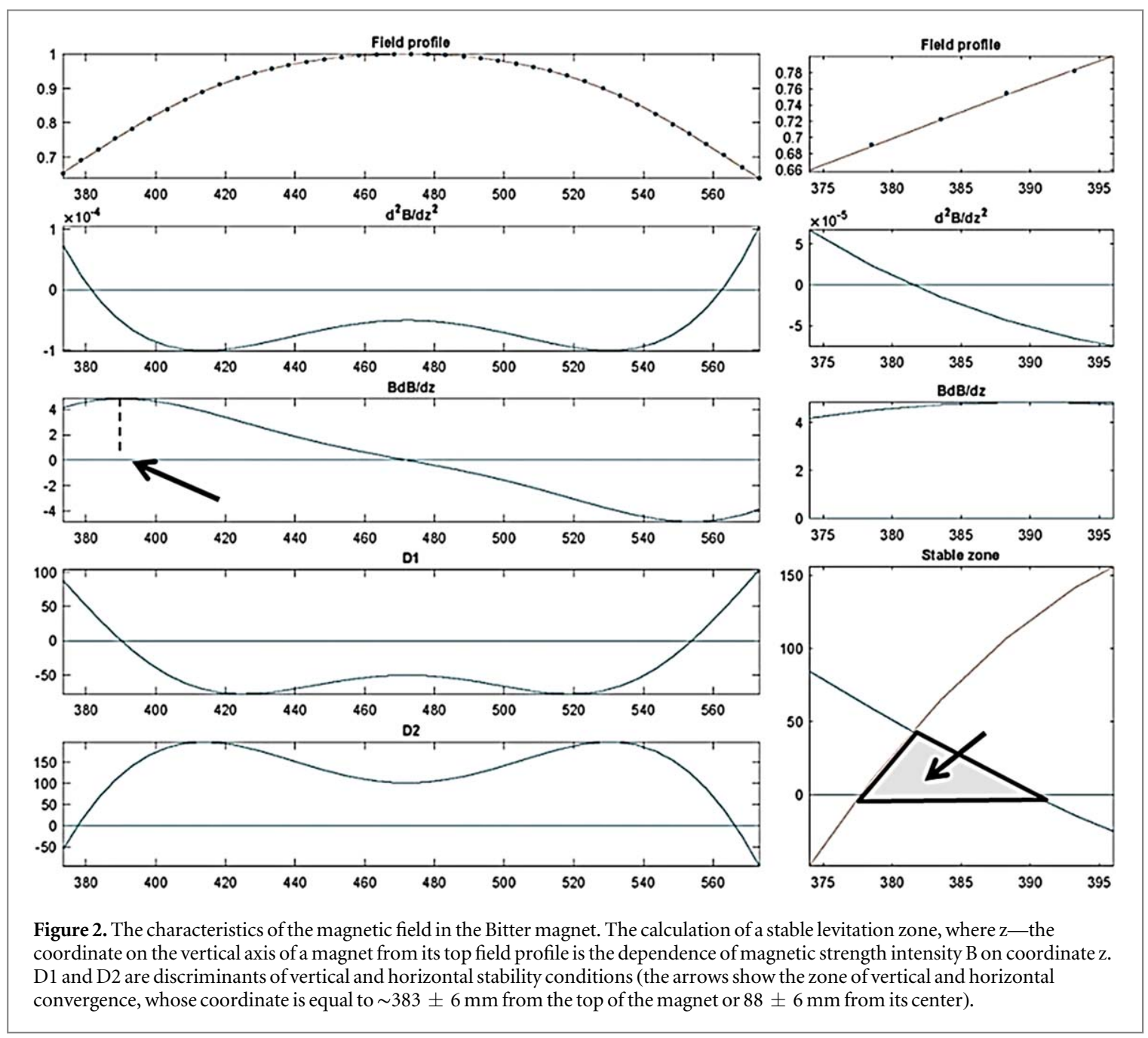

confirmed their viability and capacity to migrate from the surface during the tissue fusion process (figure 4(b)). As shown in figure 4(b), the intersphere angle increased as a function of time, and in $20 \mathrm{~h}$, after the beginning of incubation, the intersphere angle increased up to $179^{\circ}$ indicating complete spheroid fusion.

To quantitatively evaluate the toxicity of gadobutrol on SW1353 tissue spheroids, we used a CellTiterGlo 3D kit. At a low concentration of gadobutrol ( 0.8 $\mathrm{mM}$ ) the tissue spheroids were $100 \%$ viable, whereas at a high concentration of gadobutrol $(100 \mathrm{mM})$ viability decreased down to $70 \%$ in $24 \mathrm{~h}$ (figure 4 (c)). Having taken into account the fact that the complete spheroid fusion takes at least $20 \mathrm{~h}$, such cytotoxicity is crucial.

We also performed TEM studies of cells and tissue spheroids incubated at a high concentration of gadobutrol $(50 \mathrm{mM})$. As shown in figure $4(\mathrm{~d})$, in the absence of gadobutrol (control) no ultrastructural changes were observed. TEM showed that $50 \mathrm{mM}$ gadobutrol caused cell injury (figure 4(e)) accompanied by intracellular dystrophy, which correlated with the previous reports $[3,27,28]$. The toxic effect of gadolinium(III)-based gadobutrol at high concentration $(>50 \mathrm{mM})$ on cell ultrastructure usually includes: (i) margination of nuclear chromatin (figure 4(f)), (ii) swelling and reduction in the number of cristae in mitochondria (figure $4(\mathrm{~g})$ ), (iii) enlargement of the endoplasmic reticulum (figure 4(h)), as well as (iv) formation of phagosomes (figure 4(i)) and (v) severe vacuolization of the cytoplasm (figure 4(j)). It is worth mentioning that this set of ultrastructural changes is irreversible as it does not improve after 1-2 day incubation in gadolinium-free medium. In the case of a low concentration of gadolinium the ultrastructure remains intact. Taken together the reported observations strongly indicate cell and tissue viability and the absence of ultrastructural changes in cells of tissue spheroids after their incubation with low doses of gadobutrol.

\subsection{Assembly of tissue-engineered construct from tissue spheroids in a high magnetic field}

The assembly during levitation of tissue spheroids was carried out at a magnetic field intensity of $19 \mathrm{~T}$ and a concentration of $0.8 \mathrm{mM}$ gadobutrol. In contrast to polystyrene beads (figure 5(a)), the process of tissue spheroid assembly (figure 5(b)) took $40 \mathrm{~min}$, which results from some differences in magnetic properties between polystyrene beads and tissue spheroids and the difference in intensities of the magnetic field used. 


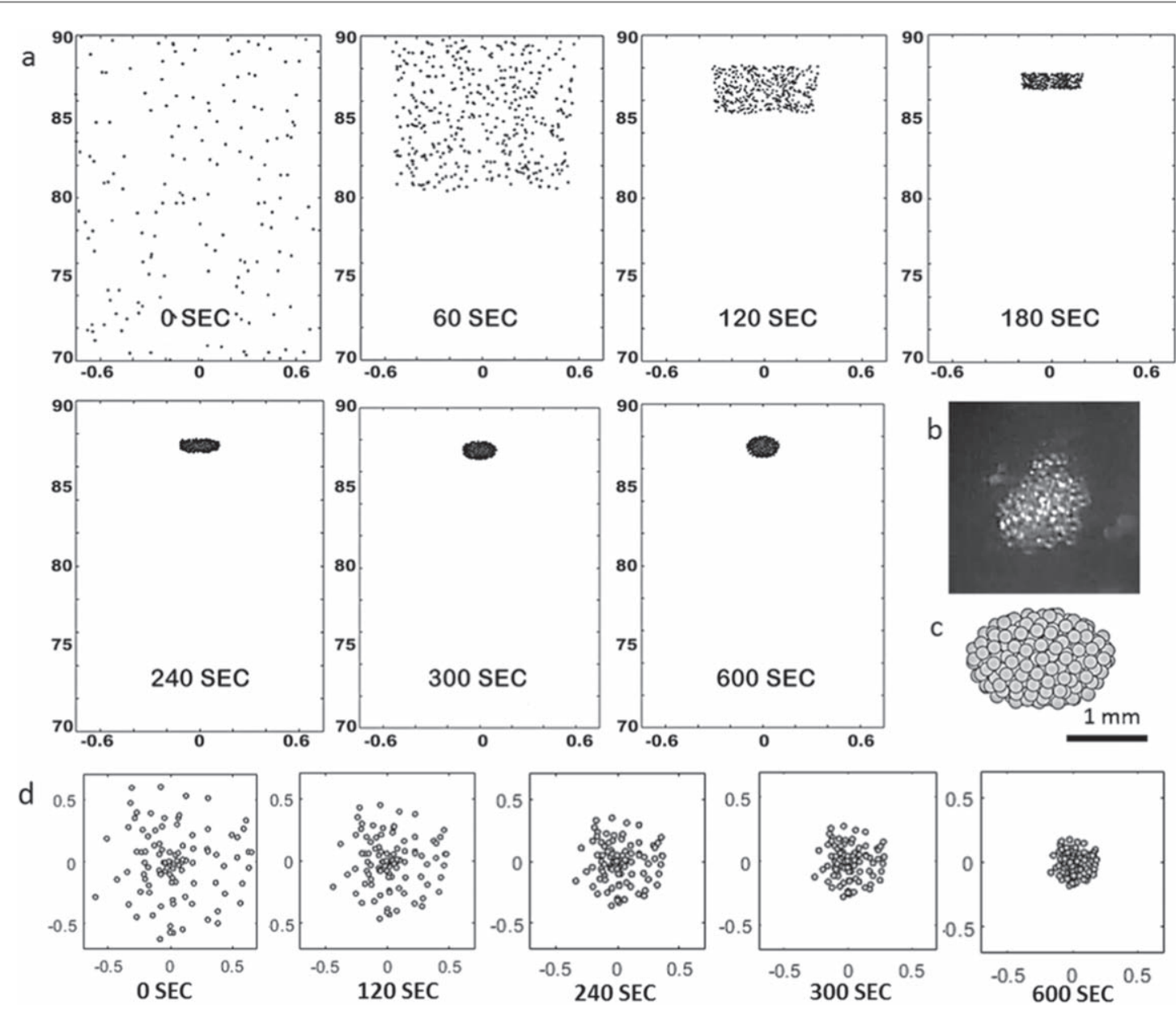

Figure 3. MD simulation of the construct assembly in the magnetic trap for polystyrene beads. The number of beads is 400 , and the diameter is $175 \mu \mathrm{m}$. (a) Assembly stages in the MD modelling (side view); (b) the appearance of constructs after experimental assembly; (c) the appearance of constructs after modelling assembly (measurement units along the axis—mm, vector $\mathrm{g}$ oriented in the vertical down direction); (d) assembly stages in the MD modelling (bottom view).

After the spheroids clustered together, the construct was kept under the same levitation conditions for $3 \mathrm{~h}$ to ensure fusion of tissue spheroids into a single construct (figure 5(c)). The histology of the construct fragment (figure 5(c), insert circle) demonstrates intact morphology of the tissue spheroids. A series of experiments were performed to show the interdependence between the paramagnetic salt concentration in the medium, the tissue spheroids' or beads' properties and the intensity of the magnetic field to maintain a stable levitation for construct formation. The results show that these parameters can be turned, while the concentration of gadobutrol and the magnetic field applied are directly related despite some small variations between the polystyrene beads' and tissue spheroids' levitation characteristics (figure 5(d)). The beads or spheroids are initially located in the bottom of the cuvette when no magnetic field is applied independently of the gadobutrol used in this study. Upon screening of different magnetic fields and gadobutrol concentrations it was possible to define trend curves that were used to define the threshold values to achieve a levitation state. Figure $5(\mathrm{~d})$ shows the threshold values required to promote polystyrene bead or tissue spheroid levitation, where areas above the curve mean that objects levitate in the vertical direction upwards; the area below the curve means that the objects are not levitating. These data demonstrate that magnetic levitation of both polystyrene beads and tissue spheroids is possible in a high magnetic field at a low non-toxic concentration of gadolinium salt (figure 5(d)).

We performed a Live/Dead assay for tissue spheroids after incubation in $0.8 \mathrm{mM}$ gadobutrol in the high magnetic field (19 T). In the low concentration of gadobutrol the high magnetic field provides levitation of tissue spheroids without affecting their viability (figure 5(e)). It was also confirmed by TEM, which did not identify strong ultrastructural changes (figure 5(f)). Taken together, these data strongly indicate the maintenance of the tissue spheroids' viability exposed to the combination of a high magnetic field $(19 \mathrm{~T})$ and a low concentration of gadobutrol $(0.8$ $\mathrm{mM})$. Thus, our theoretical and experimental data demonstrate, for the first time, that magnetic levitation assembly based on tissue spheroid fusion at a non-toxic concentration of gadolinium in a high 


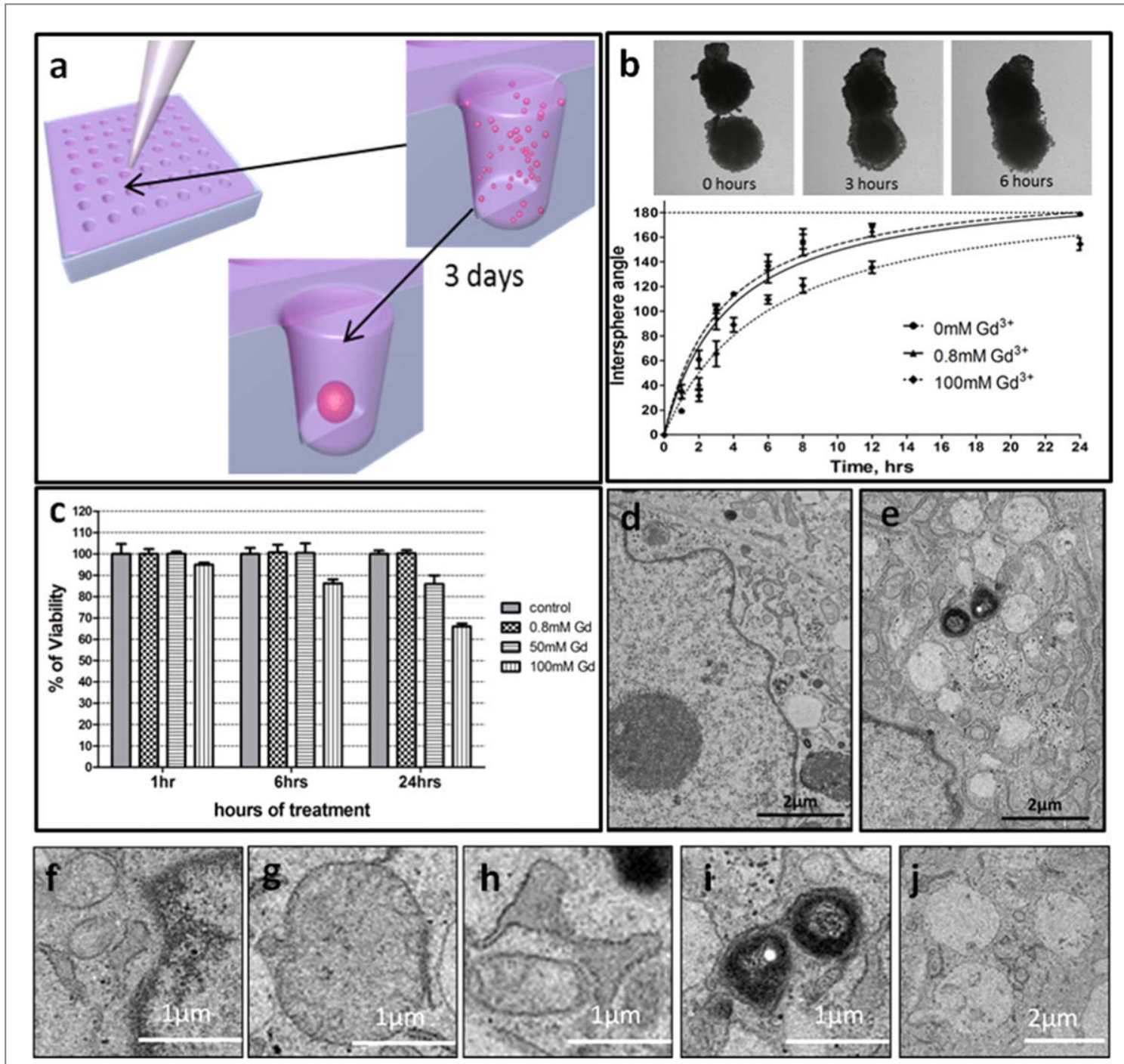

Figure 4. The toxicity of gadobutrol and the magnetic field. (a) The fabrication of spheroids using non-adhesive agarose molds; (b) the fusion of spheroids in the presence of $0.8 \mathrm{mM}$ gadobutrol (top) and the time-curve of intersphere angles during the fusion (bottom); (c) the viability of spheroids at different concentrations of gadobutrol $(0,0.8,50,100 \mathrm{mM})$; (d) a TEM image of tissue spheroids in the absence of gadobutrol (control); (e) a TEM image of tissue spheroids in the presence of $50 \mathrm{mM}$ gadobutrol (sample); (f)-(j) ultrastructural changes in cells within tissue spheroids caused by a high concentration of gadobutrol (50 mM): (f) margination of nuclear chromatin; (g) swelling and reduction of the number of cristae in mitochondria; (h) enlargement of the endoplasmic reticulum as well as; (i) formation of phagosomes; (j) severe vacuolization of the cytoplasm.

magnetic field is technologically feasible and can be implemented.

\section{Discussion}

We have performed, for the first time, the magnetic levitational bioassembly of a viable $3 \mathrm{D}$ tissue construct in a high magnetic field. Magnetic levitation was achieved at a very low concentration of paramagnetic medium $\left(\mathrm{Gd}^{3+}\right.$-chelate gadobutrol), almost 100 times lower than the concentration which was used in previously reported studies [17, 29]. Although gadolinium-based chelates are approved by the FDA as contrast agents for application in MRI [16], there is evidence that gadolinium chelates accumulate in human organisms (predominantly in the kidney, which leads to undesirable side effects-kidney damage in the form of so-called 'nephrogenic systemic fibrosis' [30, 31]), thus causing toxic effects. In the case of living cells, and especially for tissue spheroids, it is necessary to reduce the amount of toxic paramagnetic gadolinium chelates. Application of a high magnetic field (19 T) allowed us to reduce cytotoxic effects due to the use of lower concentrations of gadolinium salts $(0.8 \mathrm{mM})$ required for magnetic levitation. We took advantage of the existing European High Magnet Laboratory in Nijmegen and performed our experiments. It is noteworthy that the results of magnetic levitational assembly of polystyrene beads and tissue spheroids were in agreement with developed mathematical models that demonstrates their strong predictive power.

This is the first report that investigated the tissue spheroid's viability in an ultra-high magnetic field. There are only a few reported studies that have investigated animal or human cells at strong magnetic fields 


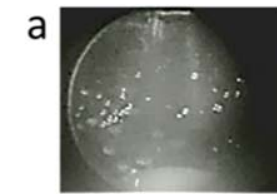

$\mathrm{T}=0 \mathrm{~min}$

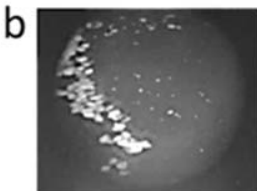

$T=0 \mathrm{~min}$

C

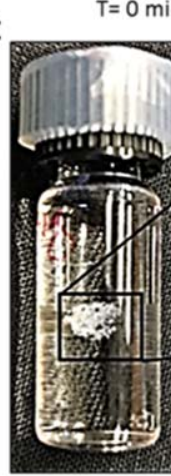

e

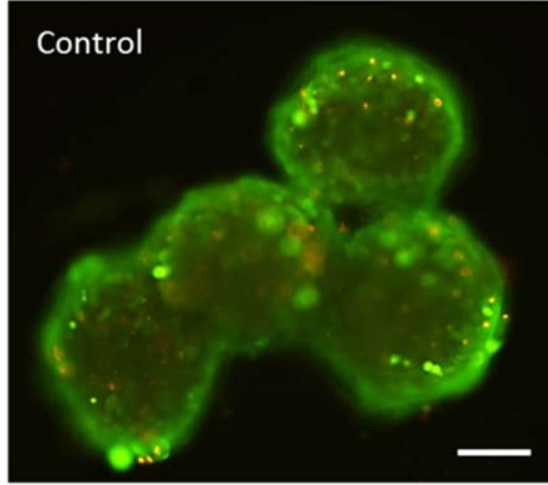

$\mathrm{T}=2 \mathrm{~min}$

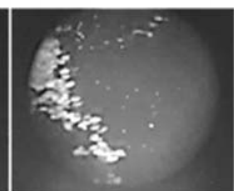

$\mathrm{T}=10 \mathrm{~min}$

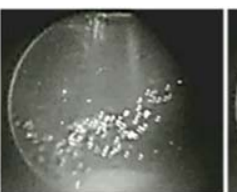

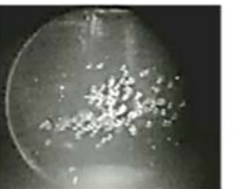

$\mathrm{T}=4 \mathrm{~min}$

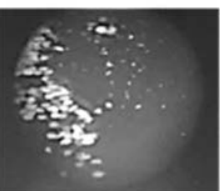

$\mathrm{T}=20 \mathrm{~min}$

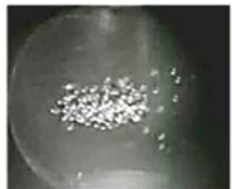

$\mathrm{T}=6 \mathrm{~min}$

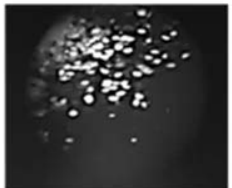

d $\mathrm{T}=30 \mathrm{~min}$

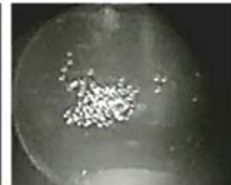

$\mathrm{T}=8 \mathrm{~min}$

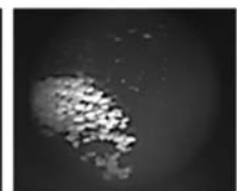

$\mathrm{T}=40 \mathrm{~min}$

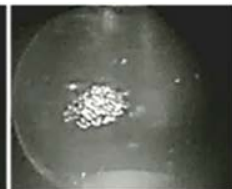

$\mathrm{T}=10 \mathrm{~min}$

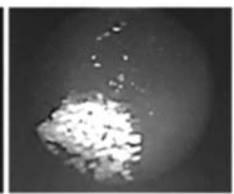

$\mathrm{T}=50 \mathrm{~min}$
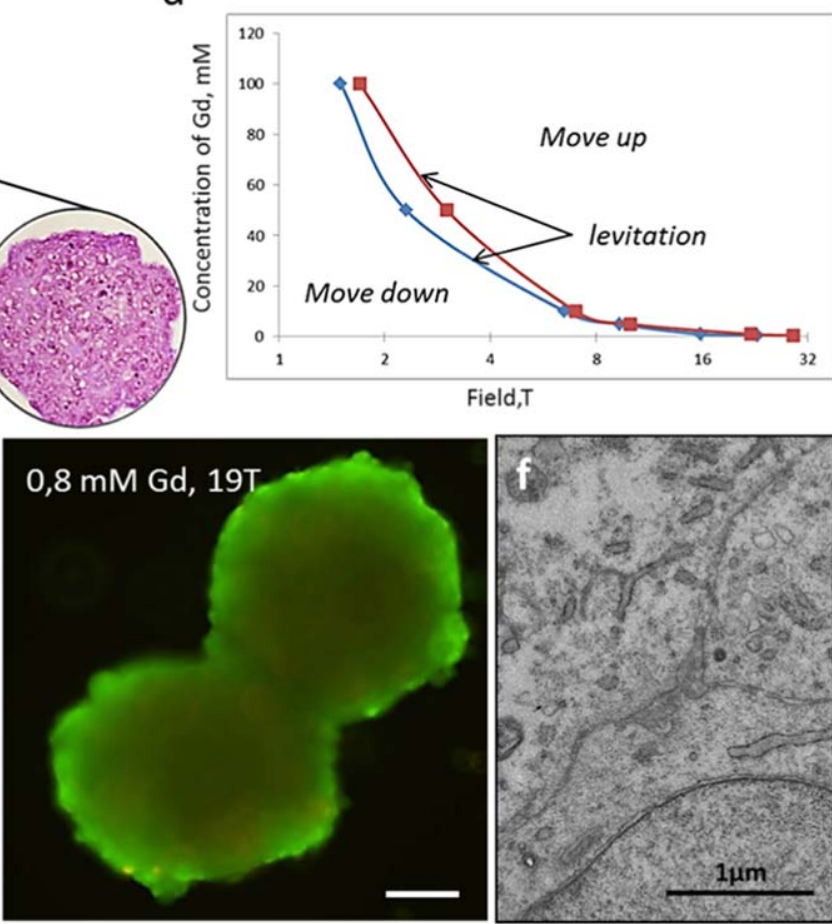

Figure 5. The construct assembly under high magnetic field levitation. (a) The polystyrene beads assembling at $0.5 \mathrm{mM}$ gadobutrol and a magnetic field intensity of $22 \mathrm{~T}$; (b) tissue spheroids assembling until a stable construct was obtained at $0.8 \mathrm{mM}$ gadobutrol and a magnetic field intensity of 19 T; (c) the construct assembled after $3 \mathrm{~h}$ at $19 \mathrm{~T}$ (insert circle shows a histological section of the construct); (d) the curves of levitation conditions depending on the gadobutrol concentration and magnetic field intensity applied for tissue spheroids (red curve) and polystyrene beads (blue curve); (e) the Live/Dead assay for tissue spheroids after $1 \mathrm{~h}$ of exposure to $19 \mathrm{~T}$ magnetic field at $0.8 \mathrm{mM}$ gadobutrol (scale bar $100 \mu \mathrm{m}$ ); (f) a TEM image of a tissue spheroid after $1 \mathrm{~h}$ of exposure to $19 \mathrm{~T}$ magnetic field at $0.8 \mathrm{mM}$ gadobutrol.

(>10 T). Nakahara et al and Zhao et al showed that 10 $\mathrm{T}$ or $13 \mathrm{~T}$ static magnetic fields did not influence the viability of human-hamster (AL) hybrid cells, Chinese hamster ovary $(\mathrm{CHO})$ cells or human primary skin fibroblasts (AG1522) [32, 33]. Valiron et al used $17 \mathrm{~T}$, and they did not observe strong killing effects on cells but they found that $17 \mathrm{~T}$ had an obvious effect on the cytoskeleton of the interphase [34]. Zhang et al used 27 $\mathrm{T}$, the highest static magnetic field strength applied on cells so far, and their results were in accordance with the data of Valiron's group [35]. To investigate the viability of tissue spheroids levitated in a high magnetic field (19 T) at a low concentration of gadolinium salts, we performed three different viability tests and revealed the experimental setup. To investigate more precisely the cell alterations after exposure to a high magnetic field, the proteomics and genomics studies of cells and tissue spheroids should be carried out in future investigations.

We did not apply any synthetic or natural scaffolds or even magnetic nanoparticles in this study and, therefore, called this technology both 'scaffold-free' and 'label-free'. In our experiments the employed high magnetic field served as some sort of 'temporal and removable support', which fits very well to the classic definition of a scaffold in tissue engineering [36]. To escape potential confusion, we previously suggested use of the new designation 'scaffield' for defining temporal and removable support provided by any type of physical fields, including the high magnetic field employed in this study [11]. We also suggested defining this type of rapid biofabrication based on using scaffield 'formative biofabrication', which is 
conceptually different from conventional 'layer-bylayer' additive biofabrication and 3D bioprinting.

It is worth mentioning that our results support the previous proposals on the use of magnetic levitation on the Earth for simulation of microgravity as a costeffective alternative to much more expensive studies of the microgravity effects on the living objects in Space, i.e. on the International Space Station.

\section{Conclusion}

The minimum concentration of gadobutrol $(0.8 \mathrm{mM})$ enabling magnetic levitation assembly was identified. The Live/Dead assay revealed minimal cytotoxicity of the magnetic field with intensity up to $30 \mathrm{~T}$ for tissue spheroids after $1 \mathrm{~h}$ of exposure. The model construct from polystyrene beads (the physical analogue of tissue spheroids) was successfully assembled at a magnetic field with an intensity of $22 \mathrm{~T}$ in $10 \mathrm{~min}$ of exposure. Constructs from living tissue spheroids (human chondrosarcoma SW1353 cell line) were assembled at $19 \mathrm{~T}$ and fusion was achieved in $3 \mathrm{~h}$. The scaffold-free and label-free formative biofabrication of tissue-engineered constructs from tissue spheroids based on magnetic levitational assembly in the high magnetic field is a technologically feasible and very promising substitute for the Space infrastructure that might increase the intensity and decrease the timeline of research. Thus, our study supports proposals to use high magnetic levitation as a cost-effective alternative to life science research on the effects of microgravity.

\section{Acknowledgments}

This work was supported by HFML-RU/NWO-I, member of the European Magnetic Field Laboratory (EMFL), RFBR according to the research project No. 18-29-11076 and the Dutch Province of Limburg. L M is grateful to the European Research Council starting grant 'Cell Hybridge' for financial support under the Horizon2020 framework program (Grant \#637308). López Iglesias, Carmen (M4i, Maastricht University) acknowledges the support with the TEM characterization.

\section{Author contributions}

V A P, C M and V A M designed the research; V A P, E $\mathrm{V} \mathrm{K}, \mathrm{F}$ D P, K A V K, C M and H E performed the research; O F P and M I M performed MD simulation of dynamics of the polystyrene particles in the cusp magnetic trap; V A P, P K, P C and H E performed computer simulation of magnetic fields; V A P, E V K and P A K analyzed the data; V A P, L M, C M, P C, E K $\mathrm{N}$ and $\mathrm{V}$ A $\mathrm{M}$ wrote the paper.

\section{ORCID iDs}

Vladislav A Parfenov (iD https://orcid.org/0000-00031234-0208

Hans Engelkamp (i) https://orcid.org/0000-00019920-0536

Lorenzo Moroni (iD https://orcid.org/0000-00031298-6025

\section{References}

[1] Beaugnon E and Tournier R 1991 Levitation of organic materials Nature 349 470-470

[2] Ikezoe Y et al 1998 Making water levitate Nature 393 749-50

[3] Ge Set al 2019 Magnetic levitation in chemistry, materials science, and biochemistry Angew. Chemie Int. Ed (https://doi. org/10.1002/anie.201903391)

[4] Berry M and Geim A 1997 Of flying frogs and levitrons Eur. J. Phys. $18307-13$

[5] Winkleman A et al 2004 A magnetic trap for living cells suspended in a paramagnetic buffer Appl. Phys. Lett. 85 2411-3

[6] Mirica KA et al 2011 Using magnetic levitation for three dimensional self-assembly Adv. Mater. 23 4134-40

[7] Xu F et al 2011 Three-dimensional magnetic assembly of microscale hydrogels Adv. Mater. 23 4254-60

[8] Tocchio A et al 2018 Magnetically guided self-assembly and coding of 3D living architectures Adv. Mater. 301705034

[9] Durmus N Get al 2015 Magnetic levitation of single cells Proc. Natl Acad. Sci. 112 E3661-8

[10] Chen P et al 2014 Microscale assembly directed by liquid-based template Adv. Mater. 26 5936-41

[11] Parfenov V A et al 2018 Scaffold-free, label-free and nozzle-free biofabrication technology using magnetic levitational assembly Biofabrication 10034104

[12] Bouyer Cetal 2016 A bio-acoustic levitational (BAL) assembly method for engineering of multilayered, 3D brain-like constructs, using human embryonic stem cell derived neuroprogenitors Adv. Mater. 28 161-7

[13] Desai P K, Tseng H and Souza G R 2017 Assembly of hepatocyte spheroids using magnetic 3D Cell culture for CYP450 inhibition/induction Int. J. Mol. Sci. 181085

[14] Raji M A et al 2014 Cytotoxicity of synthesized iron oxide nanoparticles: toward novel biomarkers of colon cancer Conf. Proc Annu. Int. Conf. IEEE Eng. Med. Biol. Soc. 2014, 6179-82

[15] Mazuel F et al 2016 Massive intracellular biodegradation of iron oxide nanoparticles evidenced magnetically at singleendosome and tissue levels ACS Nano 10 7627-38

[16] Rogosnitzky M and Branch S 2016 Gadolinium-based contrast agent toxicity: a review of known and proposed mechanisms Biometals 29 365-76

[17] Anil-Inevi M et al 2018 Biofabrication of in situ self assembled $3 \mathrm{D}$ cell cultures in a weightlessness environment generated using magnetic levitation Sci. Rep. 87239

[18] Hammer B E et al 2009 Magnetic levitation of MC3T3 osteoblast cells as a ground-based simulation of microgravity Microgravity Sci. Technol. 21 311-8

[19] Herranz R et al 2012 Microgravity simulation by diamagnetic levitation: effects of a strong gradient magnetic field on the transcriptional profile of Drosophila melanogaster BMC Genomics 1352

[20] Hemmersbach R et al 2014 Impact of a high magnetic field on the orientation of gravitactic unicellular organisms - a critical consideration about the application of magnetic fields to mimic functional weightlessness Astrobiology 14 205-15

[21] Myasnikov M I et al 2017 Coulomb scatter of diamagnetic dust particles in a cusp magnetic trap under microgravity conditions J Exp Theor Phys 124318-24

[22] D'Yachkov L G et al 2014 Two-dimensional and threedimensional coulomb clusters in parabolic traps Phys. Plasmas 21093702 
[23] Susienka M J, Wilks B T and Morgan J R 2016 Quantifying the kinetics and morphological changes of the fusion of spheroid building blocks Biofabrication 8045003

[24] Perut F et al 2018 Spheroid-based 3D cell cultures identify salinomycin as a promising drug for the treatment of chondrosarcoma J. Orthop. Res 36 2305-12

[25] Lhuissier E et al 2017 Identification of an easy to use 3D culture model to investigate invasion and anticancer drug response in chondrosarcomas BMC Cancer. BioMed Central 17490

[26] Gebauer Met al 2005 Comparison of the chondrosarcoma cell line SW1353 with primary human adult articular chondrocytes with regard to their gene expression profile and reactivity to IL$1 \beta$ Osteoarthr. Cartil. 13 697-708

[27] Tseng H et al 2013 Assembly of a three-dimensional multitype bronchiole coculture model using magnetic levitation Tissue Eng. Part CMethods 19 665-75

[28] Daquinag A C, Souza G R and Kolonin M G 2013 Adipose tissue engineering in three-dimensional levitation tissue culture system based on magnetic nanoparticles Tissue Eng. Part CMethods 19336-44
[29] Türker E, Demirçak N and Arslan-Yildiz A 2018 Scaffold-free three-dimensional cell culturing using magnetic levitation Biomater. Sci 6 1745-53

[30] Todd D J and Kay J 2016 Gadolinium-induced fibrosis Annu. Rev. Med 67 273-91

[31] Shah A H and Olivero J J 2017 Gadolinium-induced nephrogenic systemic fibrosis Methodist Debakey Cardiovasc. J. $13172-3$

[32] Nakahara T et al 2002 Effects of exposure of CHO-K1 cells to a 10-T static magnetic field Radiology 224 817-22

[33] Guoping Z et al 2010 Effects of 13 T static magnetic fields (SMF) in the cell cycle distribution and cell viability in immortalized hamster cells and human primary fibroblasts cells Plasma Sci. Technol. 12 123-8

[34] Valiron O et al 2005 Cellular disorders induced by high magnetic fields J. Magn. Reson. Imaging 22 334-40

[35] Zhang L et al 201727 T ultra-high static magnetic field changes orientation and morphology of mitotic spindles in human cells Elife 6 e22911

[36] Langer R and Vacanti J 1993 Tissue engineering Science 260 $920-6$ 